\title{
The Application Research of CAl in the Information Courses Teaching- Taking Qinghai Normal University as a Case Study
}

\author{
Dian-jun Lu ${ }^{1, a,{ }^{*}}$ Yu Wang ${ }^{1, b}$, Xiao-qin Zhang ${ }^{2, c}$, Lan-fen $\mathrm{Ji}^{3, \mathrm{~d}}$ \\ ${ }^{1}$ Department of Mathematics, Qinghai Normal University, Xining, 810008, P. R. China \\ ${ }^{2}$ Financial and Economic College, Qinghai University, Xining, 810008, P. R. China \\ ${ }^{3}$ Foreign Language Department, Qinghai Normal University, Xining 810008, P. R. China \\ adj@qhnu.edu.cn, ${ }^{\mathrm{b}}$ wangyu@qhnu.edu.cn, ${ }^{\mathrm{C}}$ zhangxiaoqin@qhu.edu.cn, ${ }^{\mathrm{d}}$ jilanfen@qhnu.edu.cn
}

Keywords: Education ;Computer Assisted Instruction; Teaching; Information Courses; Model.

\begin{abstract}
With the continuous popularization of the computer, the computer aided teaching in education has been widely used in the teaching process, and this is undoubtedly a new revolution in educational history. But some new problems worthy of attention have also exposed in the computer aided teaching process and the CAI software development. According to the characteristics of the information teaching, we take Qinghai normal university as an example, to explore the role and the significance of CAI in teaching information courses. It analyzed problems and some coping strategies in the process of using of CAI technology in the information courses teaching.
\end{abstract}

\section{Introduction}

With the arrival of information age, the social requirements have been put forward for the computer assisted instruction (CAI)-this emerging of education technology. In the information society, information has become the important resources to promote economic development, increase productivity, enhance national power; Information industry has become the important pillar industry, the number of people engaged in information industry in a country is more than the number of people engaged in other industries. Education as a product of social development, facing the serious challenge of information society, must make all sorts of reforms, to adapt to the need of social development. We need to broaden the education concept and set up the system of lifelong education. In school education, we no longer treat imparting knowledge as the only goal of the teaching, and what we mainly need to do is to cultivate the students' intelligence.

Students learn at school today, would be the indispensable content when they get their jobs. In school, in addition to teaching students computer courses and making them understand and master the application of computer, the teacher also use computer equipment to teach other subjects, and then the computer aided teaching arises as the new type of education technology.

As a normal university, the application of CAI in Qinghai Normal University has been paid more and more attention to. We not only increase the investment in hardware aspect, we also do constant innovation in teachers' information technology training and the training of network course software. Information courses teaching accounted for a large proportion in the training of undergraduate students in information and computation science and graduate students in algebra combination and cryptography in mathematics department of Qinghai Normal University. CAI has important application value in the teaching these courses.

\section{Effect and significance}

In this paper, teaching mode of many information courses for undergraduate students in information and computation science and graduate students in algebra combination and cryptography in mathematics department of Qinghai Normal University is studied and discussed. Mainly aimed at 
"mathematics", "Visual C ", "geometry drawing board" and flash, PPT and other teaching methods and curriculum integration of computer graphics and discussed with the model.

To improve student's learning initiative and independence. Application of computer auxiliary teaching means can give students a larger initiative and independence and the student learning is not limited by time of classroom teaching.

Improve the students' interest in learning information courses. Interest is the best teacher, it can arouse the students' interest in learning and their strong thirst for knowledge, it plays an important role in giving a successful class.

To improve students' visual effect in learning information courses. In learning "raster graphics generation", for example, we use the geometric sketchpad to demonstrate lively of generating processes of straight line, round, oval and it improved visual effect of learning.

It can be applied to experimental simulation and teaching difficult points. Understanding of computer graphics applications, for example, we chose the three dimensioned animation courseware, through the animation completed experiment simulation, stimulate students interest, at the same time also greatly accelerated the speed of understanding.

To enhance the teaching effect. According to the characteristics of being a large number of graphical presentation in information courses, using the geometric sketchpad demo function to make a large number of graphical presentation courseware in classroom presentation can greatly enhance the teaching effect.

\section{The problems existing in the computer aided teaching}

One-sided emphasis on the importance of CAI teaching software. The requirements of the teaching reform can integrate information technology and curriculum more closely, so in the open class or race course, we use all of the information technology and curriculum integration as an important evaluation parameter so that many teachers have to take time to make CAI teaching software.

The use of every software requires a long learning process, in this way, the CAI teaching software production became a non-professional personnel's professional work, teachers have to spend more time to make the courseware.

In the design of CAI teaching software, if teachers blindly go for perfect and ignore the essence of reality, eventually it will break the intuitive principle of teaching theory.

Intuitive principle requires teachers fully rely on students' various senses in the teaching process, so that the students can master knowledge and skills on the basis of direct perception, this awareness can help students to understand the problem directly and deepen their memory.

Using computer and multimedia can only play an auxiliary role in the teaching process; teacher still plays a leading role in classroom teaching. But there are some teachers who rely too much on the computer information technology, put too much emphasis on the role and function of the multimedia and present knowledge to students entirely depending on the computer multimedia despite the traditional function of the blackboard.

Teaching process is a process of demonstration and playing CAI teaching software, the teacher is restricted by the CAI software, make the classroom a lack of good link, don't attract students, formed a "teacher's auxiliary courseware" strange phenomenon, make the teacher's leading role to play in the classroom, causes students passively receiving information, can't play its role in the teaching of the subject, suppresses the students' initiative and enthusiasm, is not conducive to the development of their innovative thinking.

Lacking CAI resources and practical CAI teaching software. From quality of the CAI teaching software, because of the computer aided teaching software developed by professionals, and the developers don't have enough professional knowledge related to its disciplines is not enough, the scripts made by them are not scientific and suitable. 
Information technology level of some teachers' is not high, and the understanding of meaning function of the computer assisted instruction is not deep, the process of using computer assisted instruction lack pertinence, it is only the original simple electronic lesson plans, the contents of the blackboard writing, forms and methods are very limited.

The above various reasons caused teachers use all round CAI teaching software including the teaching plans, blackboard writing and teaching materials. The teachers only speak what the books say, and constrained interaction between teachers and students, it makes little difference between multimedia assisted teaching courses and the traditional classroom, its teaching effect is not as good as the traditional teaching.

CAI teaching model does not adapt to teaching software. In the process of computer assisted teaching, the choice of teaching software will determine the effect of classroom teaching, and how to choose a computer aided teaching software has become the current main problems.

To choose scientific and proper teaching software, we must be clear about the computer aided teaching pattern.

Common CAI teaching modes are as follows: one is the simulation experimental CAI, this kind of teaching software is mainly used in the physical or chemical reaction experiment, etc. Two is to demonstrate the CAI, this kind of teaching software is mainly used in the process of abstraction of mathematics, physics and presentation; Three is self test practice, the software can be applied in autonomous learning or phase study inspection; Four is the CAI teaching type, it is suitable for lectures or autonomous learning

However, because of information technology in our country starts late, the pace of the CAI software system development is slow, talent team who especially know both technology and understand the subject are scarce. Some primary and secondary schools of public basic courses or hot subject courseware are mainly used in the field of education at present, there is no more scientific and reasonable CAI teaching software except some information disciplines having electronic reading.

Courseware structure is unreasonable, it lack of stimulating and interactive. Instructive principles in teaching theory is that the teacher wants to mobilize students' learning initiative and enthusiasm in the teaching, make their own positive thinking, understand and grasp the learning content, and knowledge can be creatively applied in practice, to improve students' ability to analyze and solve the problems.

However, most of the current CAI teaching software only pay attention to the program design, ignoring the structure, and regardless of primary and secondary, content is multifarious, in the actual teaching it has less function and effect.

Some courseware are directly from the textbook content, and even the transitional paragraph text are moved to the courseware, making courseware in disorder. Some courseware only pay attention to the design of picture, not paying enough attention to teaching content, so students only noticed the picture while ignoring the teaching content, not understanding and grasping the content of the learned.

Some courseware are not from the perspective of students when the designing, only from the technical level of design, computer as a basic tool to present information completely, ignore the rule and characteristics of students' physical and mental development, lack of interaction, the CAI software and the traditional books are not meaningful.

\section{Coping strategies of Computer aided teaching problem}

Strengthen management to know the CAI application value. In the process of computer aided teaching, both in school and the education administrative department need to relocate, rethink the application of computer aided teaching value and strengthen macro management. 
In terms of teaching management, school should improve the teaching of computer aided system, introduced policies conducive to its development, and increasing investment in hardware and funds, etc. Teachers should be asked to make full use of computer assisted instruction to strengthen management at the same time, making the CAI embody "teaching theory" being objective, scientific, thoughtful and inspiring, consolidate, integrity principle, giving full play to the positive role of CAI in the education teaching.

Strengthen the training, and constantly improve the information literacy of relevant personnel. To promote the healthy and rapid development, computer assisted instruction must do a good job of training personnel. The leadership is dominant, the teacher is the core, and the student is the main body. Therefore, you must pay attention to the school leaders, teachers and students of three levels of information literacy and ability training.

To improve information literacy of leaders. In school, the computer aided teaching of key decision makers is head of the school, the computer assisted instruction to determine whether the school should develop computer-aided teaching. If we want to let the leaders know "why" and "how" to develop computer aided teaching, we can increase the exchange and training of the school leadership, school leaders can have a more full understanding of the advantages of computer assisted instruction and issues related to development, at the same time knowing how to develop related knowledge and ability of computer aided teaching.

The cultivation of teacher's information literacy. In school, the teacher is the core of the computer aided teaching and teachers' information literacy determines the success or failure of computer aided teaching.

Therefore, we must strengthen the training of CAI course teachers, make them master the basic skills of using multimedia hardware platform, and can use its relevant platform to make relatively simple, suitable teaching software.

Training needs to be targeted, according to the subject characteristics of grading, levels, focusing on short-term training, to improve their information literacy and the ability of computer application.

If teachers don't have the corresponding ability and quality, it will not be able to adapt to these changes, which affects the smooth implementation of computer aided teaching. For this, we must take certain incentives, create a good atmosphere of CAI, motivated teachers to applied research and innovation of CAI.

The improvement of students' ability. The teachers are in a dominant position in the teaching process, and students possess the subject status in the whole process. In the current computer assisted instruction, especially the CAI courseware, mainly include: type teaching courseware is given priority to the teacher and for the test in which take students self-study as principal or demonstration courseware. Taking Qinghai Normal University as an example, the school computer education is carried out through the teacher's explanation, demonstration and experimental way, pay too much attention to the cultivation of the student's ability to understand the computer knowledge, ignore the improvement of the quality of computer application, this makes "student learning, only and do not know why" situation.

To solve this problem, we must learn to adjust the content and methods, should give priority to studying computer applications software, improve computer application ability, to implement the teaching work, improve the teaching effect.

\section{Strengthen the construction of CAI network database}

In the aspect of strengthening the construction of CAI network resource, we should construct relatively rich CAI network resource according to actual needs. CAI network resource mainly includes material resources, management system of teaching resources, network, general teaching system support platform software, hardware, etc. First of all, we can buy or make text, animation, 
pictures, sound and other material related to school curriculum resources and teaching resource management system.

Secondly, with the continuous development of network technology, network course construction and network courseware has become a main task in the current computer assisted instruction.

We should set up corresponding CAI network laboratory and related specialized professionals to do network curriculum construction and the design and development of CAI courseware, making multimedia courseware can spread to the teachers and students through the network.

Also we can form CAI development and application group, teachers and develop personnel formed a relatively stable CAI team, decompose the content of different disciplines, make a small and exquisite of CAI courseware, set up schools CAI network resource, manage through the network teaching platform, let each teacher obtain from the platform and the use of network resources according to own actual situation.

In raising the quality of the development of CAI teaching software, we need to pay attention to the design of teaching software. Designing the teaching software is the core and key of computer assisted instruction, it plays a decisive role in the success or failure of the whole teaching system. Good CAI teaching software should be in accordance with the thought of education software engineering research, development and management, from the script design, material collection, writing production to commissioning, should be around the curriculum standard, combining with the characteristics of CAI software and teaching target, content and methods skillfully throughout the software design process, the simplification, the problem of complex abstract problem specific, continuity of old and new knowledge, to make full use of computer multimedia, accurate, fast, flexible, vivid, and the advantages of efficient, fully arouse learners' various senses, activating their thinking, make its active learning, so as to help students understand the textbook knowledge, both inside and outside the classroom expand student aspect of knowledge, improve the efficiency of classroom teaching.

\section{Summary}

This article studied and discussed information class curriculum teaching model of information and computation science majors and 2013 professional algebra combination of computational mathematics and cryptography direction graduate students' in department of mathematics of Qinghai Normal University.

CAI can improve students' learning initiative and independence, improve the students' interest in learning information courses, to improve students' study of visual information course, and enhance the effect of the computer aided teaching, and so on. In the current information class curriculum teaching, the existing problems put one-sided emphasis on the importance of CAI teaching software, CAI resource is scarce, we lack practical teaching software, software type and teaching pattern does not adjust, and structure of teaching courseware is unreasonable, etc. To solve these problems, we should strengthen management, to recognize CAI application value, strengthen training, improve the relevant personnel of the information literacy, at the same time to strengthen the construction of CAI teaching resource database.

\section{Acknowledgments}

The research was supported by Qinghai Normal University Teaching Research Funds QSJZ[2013]43, and by the Ministry of Education Chunhui Program JWSL[2014]1310.

\section{References}

[1] S. F. Tang, Principles of computer composition, Higher Education Press: Beijing, 2008. 
[2] Y. X. Lu \& X. Yang. The Course of practical University computer English, Mechanical industry publishing clubs: Beijing, 2009.

[3] R. Q. Liu, S. F. Zhong, The application of CAI in computer education and research, The Science Education Article Collects Total: 2013, 12 (2 62 ) 76-78.

[4] O. Ismail, A. Muraina Imran, A. Adeleke Mukaila, 2011. Computer Assisted Instruction For Teaching/Learning Process And Its Effects On Students' Performance In Tertiary Institutions, International Journal of Computer Trends and Technology.

[5] F. F. Shen, H. G. Wang, Y.J. Yu, The application of computer assisted instruction and multimedia in teaching genetics, HEREDITAS (Beijing), 2000, 22(1): 34-36.

[6] R. Q. Liu, S. F. Zhong, Application and Research of CAI in Computer Education, The Science Education Article Collects, 2013,262(12):76-78. 